\title{
Scissors in Brain: An Unusual Presentation of Tribal Culture in India
}

\author{
Beyinde Makas: Hindistan ¿da Kabile Kültürünün Alışılmadık Bir \\ Sunumu
}

Apoorva KUMAR, Rajendra PANDEY, Kulwant SINGH, Vivek SHARMA

Institute of Medical Sciences, Department of Neurosurgery, Varanasi, India

Correspondence address: Apoorva KUMAR / E-mail: apoorvakumar80@gmail.com

\begin{abstract}
AIM:To observe the neurological complications arising from various tribal practices and their management. Penetrating head injuries comprise only a small number of total head injuries. A penetrating head injury by deliberate attempt to treat an ailment is almost unheard of.

MATERIAL and METHODS: We present here a case of penetrating head injury caused by stabbing a scissor in head by a local witch doctor in order to treat a psychiatric ailment.

RESULTS: The patient was taken up for for surgery and managed accordingly. Relevant literature was reviewed regarding various foreign bodies in traumatic missile and non missile brain injuries and their surgical management.
\end{abstract}

KEYWORDS: Penetrating injury, Brain, Scissors, Tribal culture, Head injury

ÖZ

AMAÇ: Çeşitli kabile uygulamalarından kaynaklanan nörolojik komplikasyonların ve bunların tedavilerinin gözden geçirilmesi. Penetran kafa yaralanmaları tüm kafa yaralanmalarının sadece küçük bir kısmını oluşturur. Bir hastalığı tedavi etmek amacıyla kasıtlı olarak yapılan penetran kafa yaralanması ise neredeyse hiç duyulmamıştır.

YÖNTEM ve GEREÇ: Biz burada psikiyatrik bir rahatsızlığı tedavi etmek amacıyla yöresel bir büyücü doktor tarafından kafasına makas saplanarak penetran kafa yaralanması olmuş bir vaka sunuyoruz.

SONUÇ: Hasta ameliyata alındı ve uygun şekilde tedavi edildi. Kurşuna bağlı olan ve olmayan travmatik beyin yaralanmalarındaki yabancı cisimler ve bunların cerrahi tedavileri ile ilgili literatür gözden geçirildi

ANAHTAR SÖZCÜKLER: Penetran yaralanma, Beyin, Makas, Kabile kültürü, Kafa yaralanması

\section{INTRODUCTION}

Severe penetrating head injuries caused by pointed objects account for about $0.4 \%$ of all head injuries [1. Anderson SA, Story PG: Case study of an orbital screwdriver injury J Ophthalmic Nurs Technol 15:103-104, 1996., 4. Evans RJ, Richmond JM: An unusual death due to screwdriver Impalement: A case report. Am J Forensic Med Pathol 17:7072, 1996., 7. Ishikawa E, Meguro K, Yanaka K, Murakami T, Narushima K, Aoki T, Nose T: Intracerebellar penetrating injury and abscess due to a wooden foreign body. Neurol Med Chir (Tokyo) 40:458- 462, 2000]. Psychiatric disorders in rural and tribal India are not an identified entity and are considered by many as the effect of evil spirits on the patient. The treatment providers are usually the witchdoctors or the local quacks. Treatment varies from administration of local herbs, prayers or some bizarre procedures as we are going to report.
We report the case of a patient who had a history of irrelevant talks for some time and was treated by insertion of scissors in the brain by a local witchdoctor.

\section{CASE REPORT}

The patient is a 25- year -old male resident of the tribal areas of Jharkand with a history of irrelevant talks for 6 months, sleeplessness for 4 months and episodes of running away from home for 4 months. The attendant gave history of the patient seeing imaginary people and was afraid that they would hurt them. The patient was taken to a local doctor but his medication did not help. Financial constraint prevented the family from visiting any higher medical centre in the city. The attendants finally resorted to a witchdoctor who told them that the patient was under control of an evil spirit and the spirit was commanding the patient. Initially the patient was treated by local herbs and religious ceremonies but the 
patient was not relieved. At this point the witchdoctor told the family that the connection of the spirit from the patient has to be cut. For this he would use scissors for cutting a connection.

The family members having no respite agreed to the witchdoctor's wish. The witchdoctor brought an old scissor and stabbed the patient on the head, within a moment he tried to take out the scissors but scissors got struck in the skull bone. When the witchdoctor tried too hard the tip of the scissors broke from the rest of the scissors and lodged in the brain. The witchdoctor told the family members that the patient was healed and family should take him home. About three days later the patient developed right sided hemiparesis, right hemianasthesia and motor aphasia. At this point the witchdoctor was nowhere to be found. The attendants immediately rushed the patient to our institute.

Clinical Examination: The patient was in GCS E4V5M6, pupil bilateral normal size normal reaction. Right sided hemiparesis with hemianaesthesia was present with facial sparing. Power was $2+/ 5$ on all joins on the right side of body, sensory loss was evident in all dermatomes and deep tendon jerks were exaggerated. There was no bladder and bowel involvement. On local examination a small linear cut was seen on left frontoparietal region.

Laboratory investigations: all the blood chemistries were within normal limits

Radiological Examination: $X$ - ray examination in AP and Lateral view revealed a radio opaque triangular shadow on left side in the parietal region (Figure 1, 2). Computer Tomographic scan revealed the presence of a metallic foreign body in the parietal region with surrounding brain edema (Figure 3,4). A linear defect in the parietal skull bone was also observed.

Surgical Procedure: The patient was taken up for surgery. A local incision was given at the site of stab. Upon retraction

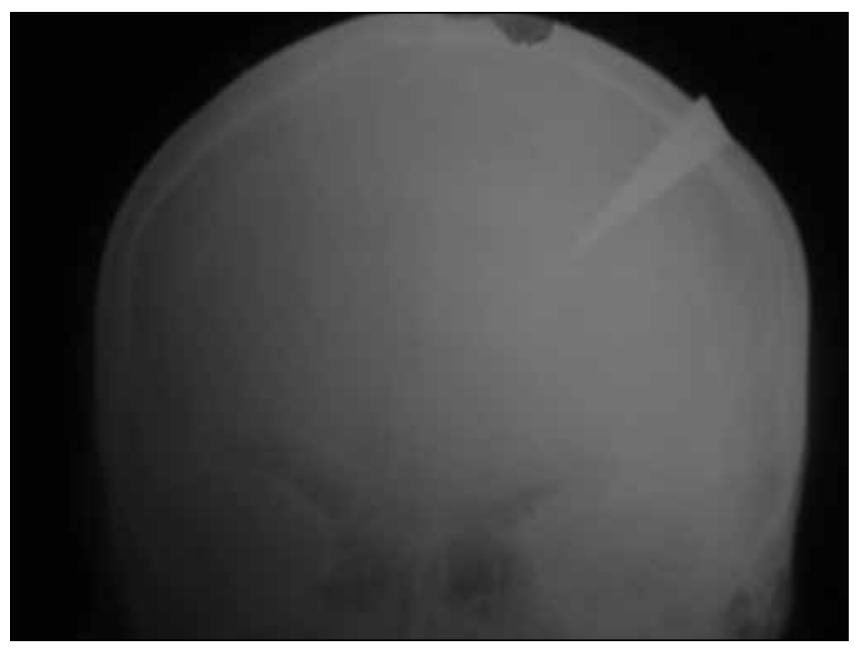

Figure 1: Skull X- ray showing foreign body in AP view.

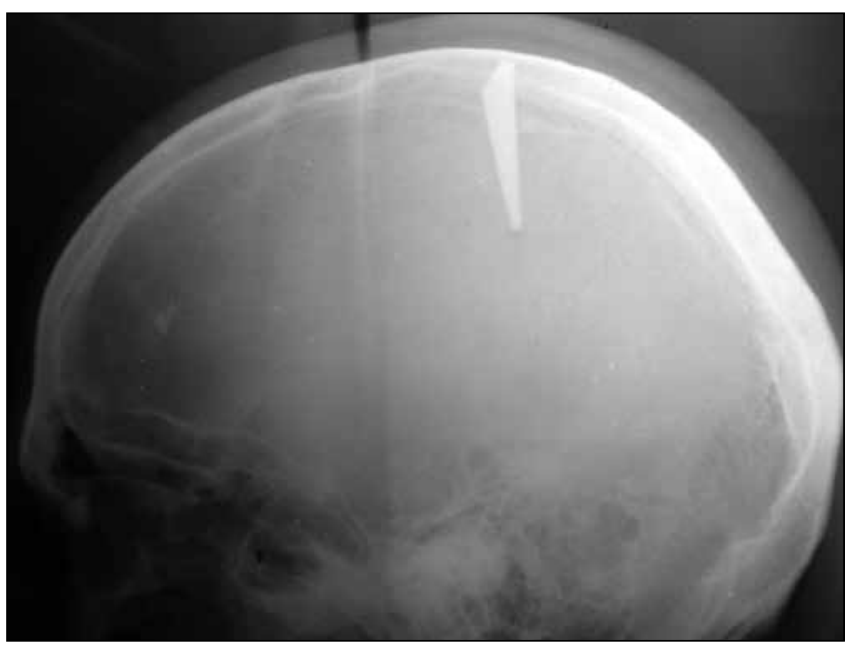

Figure 2: Skull X-ray showing foreign body in Lateral view.

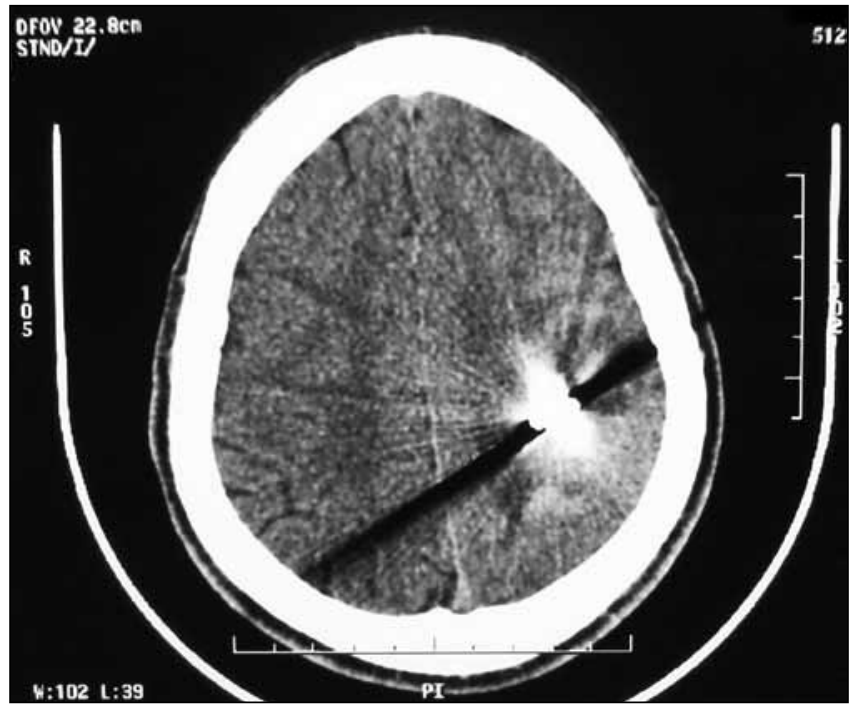

Figure 3: CT scan showing foreign body in brain matter.

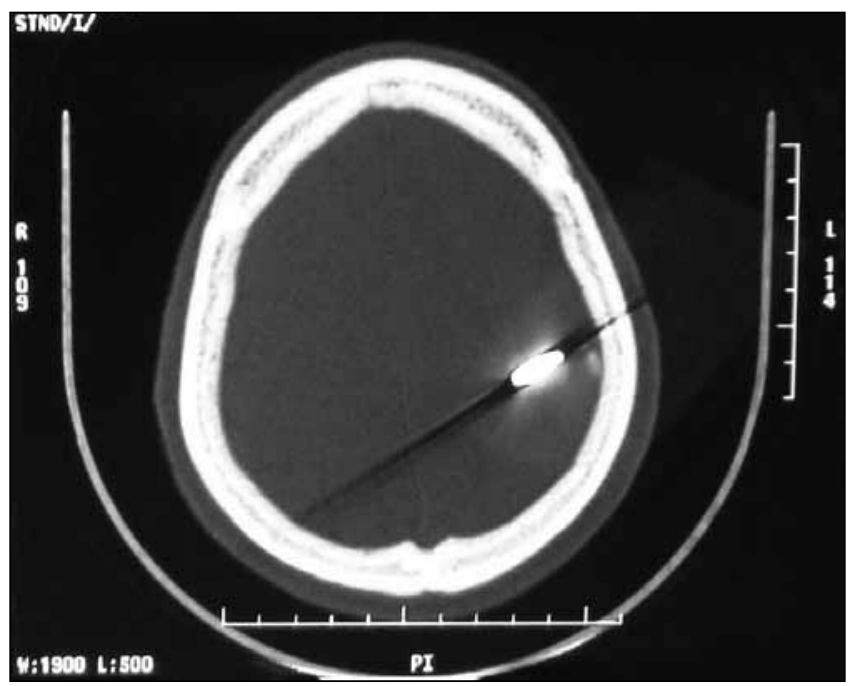

Figure 4: CT scan bone window showing foreign body. 
metallic object was seen shining (Figure 5). A burr hole was made adjacent to the stab site and circumferential craniectomy was done (Figure 6). Hematoma was found under the dura (Figure 7). Circumferential craniectomy was done to expose the metallic body completely (Figure 8 ). Scissors heads were

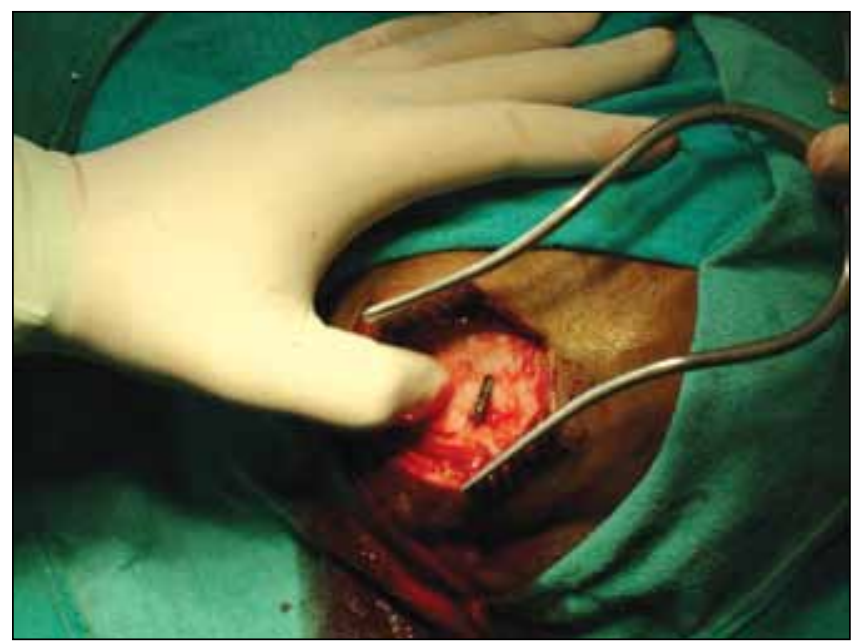

Figure 5: Entry point showing metallic foreign body after skin incision.

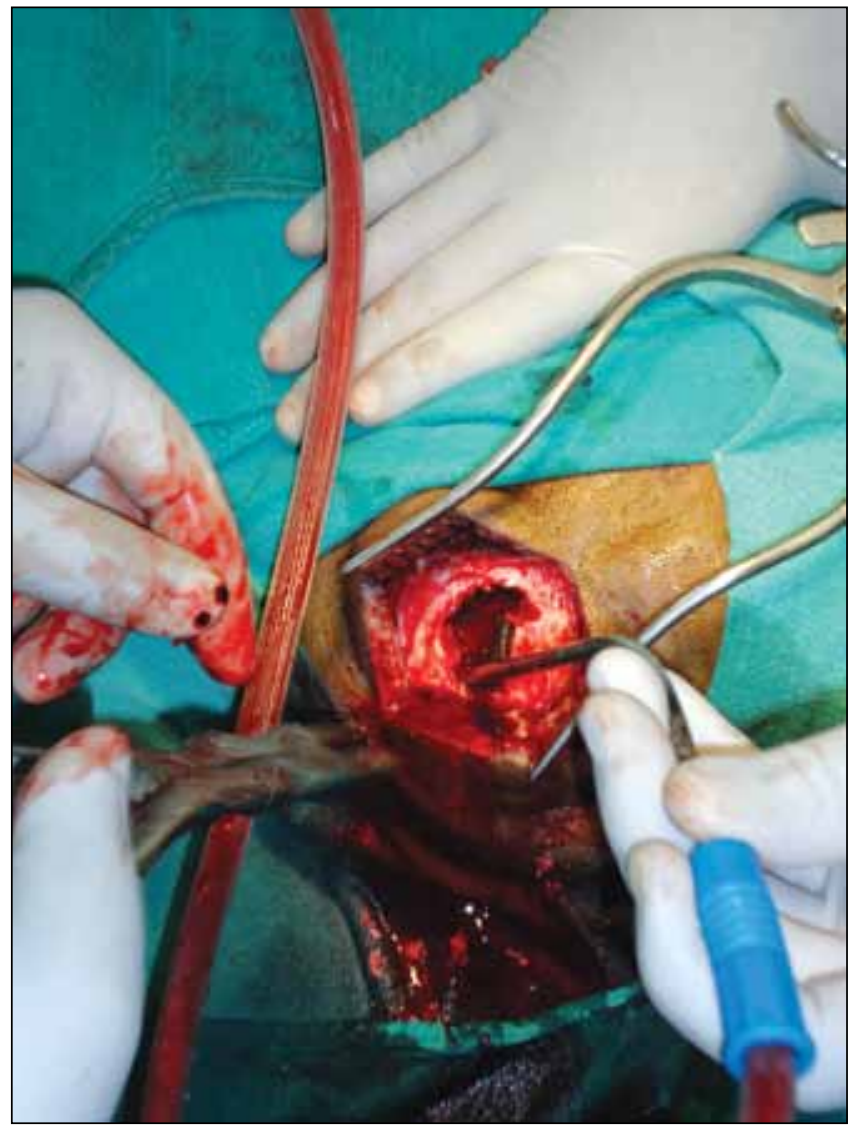

Figure 7: Craniectomy showing underlying Hematoma. removed (Figure 9) cautiously to prevent any vascular insult. Mud and chipped of pieces of rust were also removed. Local cleaning was done with saline and hydrogen peroxide. Local contused brain was decompressed. Duroplasty was done and skin was closed.

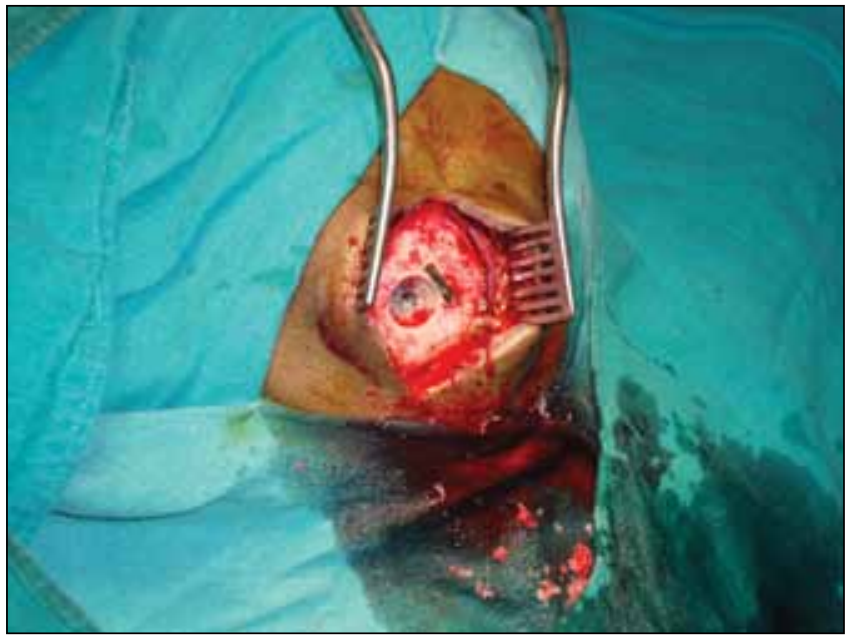

Figure 6: Burr hole made adjacent to entry site.

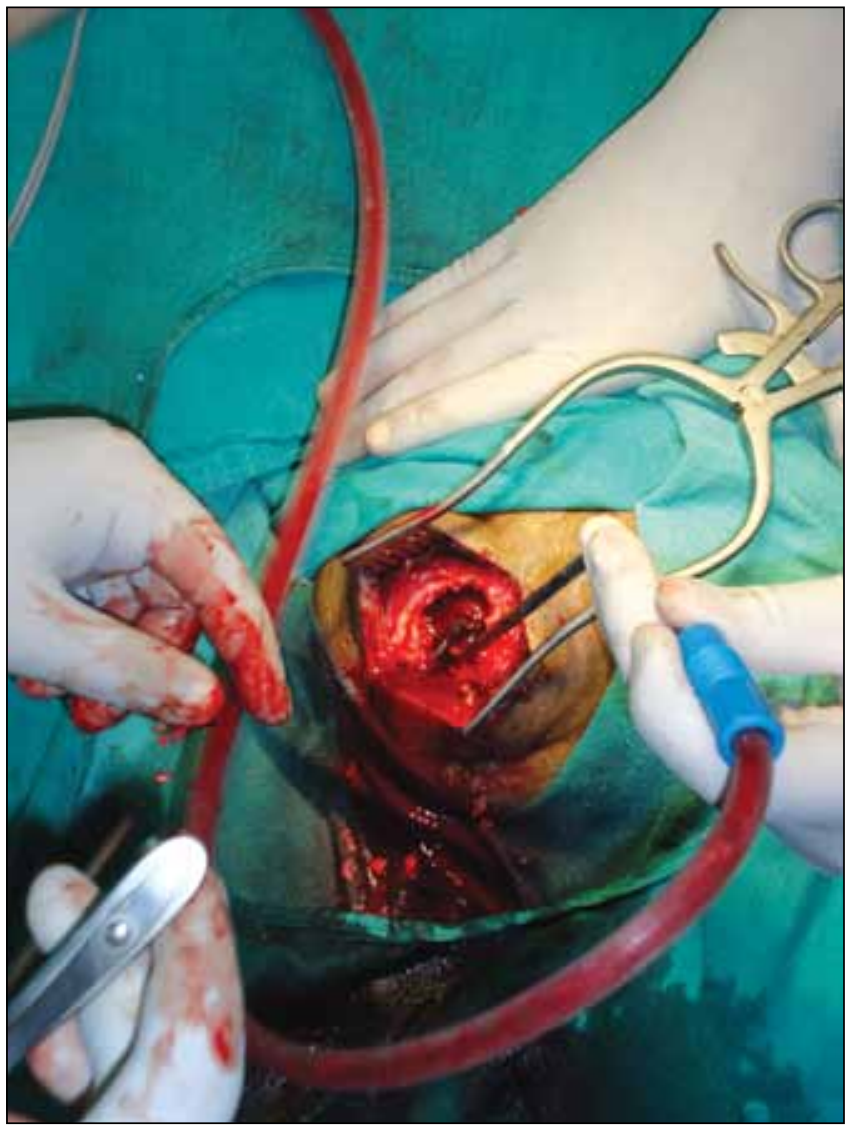

Figure 8: Full exposure of scissors heads after circumferential craniectomy. 


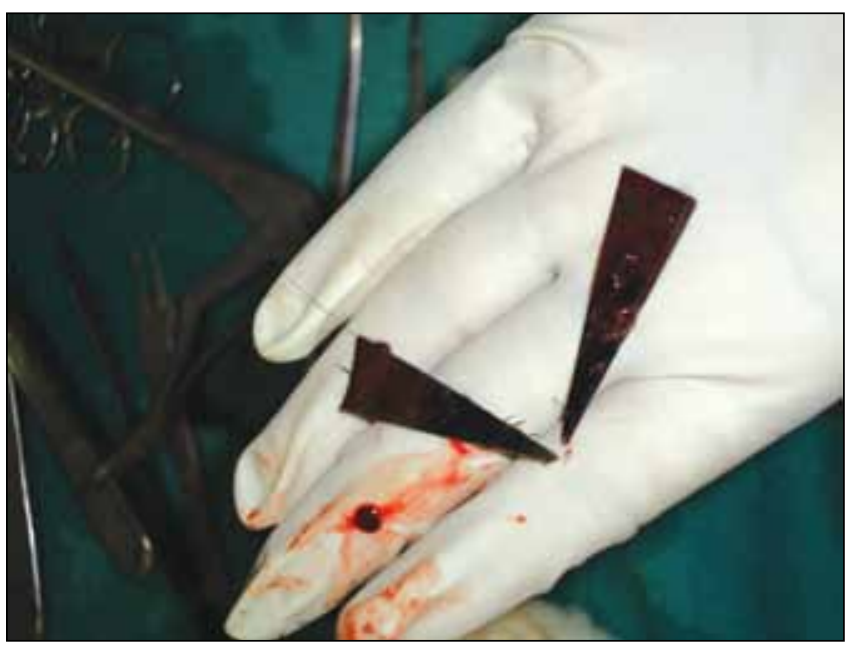

Figure 9: Scissor tips after removal.

Post Operative Period and Follow up: The patient recovered well in the post operative period. There was no wound infection or seizure episode. Till the time of discharge on the 7 th post operative day the patient had developed a power of $3+/ 5$ on all joints in right side of body. In a follow up of 2 months patient's power had increased to $4+/ 5$ and he is undergoing rehabilitation with the physiotherapy department.

\section{DISCUSSION}

Penetrating injuries of the brain are very common in War but are rare in civilian head injuries. Missile injuries account for majority of penetrating wounds of brain though brain has been penetrated by almost every conceivable object [8. Kaufman $\mathrm{HH}$. Treatment of civilian gunshot wounds to the head. Neurosurg Clin N Am 2:387-397,1991]. There are reports in literature ranging from knife, blades, spoons and even nail [3 . Davis NL, Kahana T, Hiss J. Souvenir knife: a retained transcranial knife Blade. Am J Forensic Med Pathol 25:259-261, 2004.,11. Salar G, Costella GB, Mottaran R, Mattana M, Gazzola $\mathrm{L}$, Munari M]. Multiple craniocerebral injuries from penetrating nails. J Neurosurg 100:963, 2004]. The major contributors to the range and extent of injury are the type of object, the cross section area, the rotation of the projectile in the brain and the fragments in the brain parenchyma. Standard text puts great emphasis on the velocity of penetrating object, differentiating wounds into "low velocity" and "high velocity". However, velocity alone does not predict the injuring capacity of the projectile [5. Fackler ML .Wound ballistics. A review of common Misconceptions. JAMA 259:2730-2736,1988]. Three most common types of low velocity penetrating head injuries are seen in industrial accidents, suicidal attempts and as a result of criminal assaults [2. Bakay L, Glausuer FE, Grand W Unusual intracranial foreign bodies. Report of five cases. Acta Neurochir(Wien) 39:219-231,1977]. In our case the low velocity injury was caused by deliberate stabbing on the head and injury was aggravated by an attempt to remove the scissors, causing the breakage of the proximal blades.
Possibility of contamination by rust and earthen flora necessitates prompt and meticulous management of these cases. Immediate radiological examination is mandatory because small entrance wound does not correspond with the size of foreign body and associated intracranial injury.

X-ray skull is useful to delineate the depth and direction of penetration [6. Herring CJ, Lumsden AB, Tindall C. Transcranial stab wounds. A report of three cases and suggestions for management. Neurosurgery 23:658- 662, 1988.]. X rays also stand as good evidence in the court of law if the offender goes under a trial. CT scan head is mandatory in all cases to know the extent of intracranial injuries and is essential in decisionmaking regarding approach to a surgical intervention [10 Nakayama Y, Tanaka A, Arita T, Kumate S, Yoshinga S. Penetrating head injury caused by weed: Case report. No To Shinkei. Dec; 47(12):1192-1194,1995.]. However CT scan may need a change of window levels to decrease the metal artifacts. Transcranial wounds should be explored surgically and penetrating foreign body should be removed. In our case the scissor heads were gently removed along repair of dural tear. One has to be very careful not to produce further damage to the underlying brain by movement of the foreign body and surrounding bone [2. Bakay L, Glausuer FE, Grand W Unusual intracranial foreign bodies.Report of five cases. Acta Neurochir (Wien) 39:219-231,1977.]. Any sharp foreign body like the one in our case holds a potential for any vascular injury on even the slightest mishandling. These injuries vary in severity from trivial to life threatening but the usual complications are infection and vascular. Penetrating wounds passing through paranasal sinuses or oropharyngeal mucosa before entering cranium have increased chances of wound infection.

We refrain from immediate reconstruction in penetrating injury cases because these cases have presented with increased incidence of local osteomyelitis and abscess formation.The survey of management pattern of these injuries showed a general agreement about CT scan, antibiotics and anticonvulsants [9. Kaufman HH, Schwab K., Salazar AM. A national survey of neurosurgical care for penetrating head injury. Surg Neurol 36: 370-377, 1991]. Prompt management resulted in an excellent outcome.

\section{REFERENCES}

1. Anderson SA, Story PG: Case study of an orbital screwdriver injury. J Ophthalmic Nurs Technol 15:103-104, 1996

2. Bakay L, Glausuer FE, Grand W: Unusual intracranial foreign bodies. Report of five cases. Acta Neurochir (Wien) 39: 219-231,1977

3. Davis NL, Kahana T, Hiss J: Souvenir knife: A retained transcranial knife Blade. Am J Forensic Med Pathol 25: 259-261, 2004

4. Evans RJ, Richmond JM: An unusual death due to screwdriver Impalement: A case report. Am J Forensic Med Pathol 17: 70-72,1996 
5. Fackler ML: Wound ballistics. A review of common misconceptions. JAMA 259:2730-2736,1988

6. Herring $C J$, Lumsden $A B$, Tindall $C$ : Transcranial stab wounds. $A$ report of three cases and suggestions for management. Neurosurgery 23: 658- 662, 1988

7. Ishikawa E, Meguro K, Yanaka K, Murakami T, Narushima K, Aoki T, Nose T: Intracerebellar penetrating injury and abscess due to a wooden foreign body. Neurol Med Chir (Tokyo) 40:458-462,2000

8. Kaufman $\mathrm{HH}$ : Treatment of civilian gunshot wounds to the head. Neurosurg Clin N Am 2:387-397,1991
9. Kaufman $\mathrm{HH}$, Schwab K, Salazar AM: A national survey of neurosurgical care for penetrating head injury. Surg Neurol 36: 370-377, 1991

10. Nakayama Y, Tanaka A, Arita T, Kumate S, Yoshinga S: Penetrating head injury caused by weed: Case report. No To Shinkei 47(12):1192-1194, 1995

11. Salar G, Costella GB, Mottaran R, Mattana M, Gazzola L, Munari M: Multiple craniocerebral injuries from penetrating nails. J Neurosurg 100:963, 2004 